\title{
Compulsion under the Mental Health Act 1983: audit of the quality of medical recommendations
}

\author{
Julian Mason, ${ }^{1}$ Hannah Roberts, ${ }^{2}$ Rebecca Northridge, ${ }^{2}$ Garyfallia Fountoulaki, ${ }^{1}$ Emma Andrews, ${ }^{3}$ \\ Cassie Watcyn-Jones, ${ }^{1}$ Terri Manion, ${ }^{2}$ Julie Chalmers, ${ }^{2}$ Phil Davison ${ }^{2}$
}

The Psychiatrist (2012), 36, 11-15, doi: 10.1192/pb.bp.111.034819

${ }^{1}$ Berkshire Healthcare NHS Foundation Trust; ${ }^{2}$ Oxford and Buckinghamshire Mental Health Partnership NHS Trust ${ }^{3}$ Kingsbridge Community College, Devon

Correspondence to Julian Mason (jules.mason@berkshire.nhs.uk)

First received 2 Apr 2011, final revision 12 Sep 2011, accepted 14 Sep 2011
Aims and method To audit the quality of medical recommendations for detention under the Mental Health Act 1983, Section 2 and 3. The recommendations were tested against a gold standard based on the statutory criteria. Two cycles were completed, the first containing 214 recommendations, the second 202. Relevant education took place after the first cycle.

Results The percentage of medical recommendations containing clear statements of why each of the statutory criteria was met increased in the second cycle. It reached $87 \%$ for mental disorder; $87 \%$ for nature and/or degree; $75 \%$ for why community treatment was not possible; $64 \%$ for why detention was in the interests of health; $60 \%$ for safety; $55 \%$ for protection of others; and $70 \%$ why informal admission was not possible.

Clinical implications Doctors, scrutineers and approved mental health practitioners welcomed clear guidance about what is expected in a medical recommendation for detention and endorsed the gold standard described. Armed with a better understanding of what is expected and a template to follow, there was an improvement in the reasons given for detention.

Declaration of interest None.
Following a Mental Health Act assessment in England and Wales, two doctors, at least one of whom should have special experience in the diagnosis and treatment of mental disorder, have to decide whether the statutory criteria for detention have been met. ${ }^{1,2}$ If they have, and a decision is made for the patient to be detained, the doctors have to give their reasons in a medical recommendation. ${ }^{3,4}$ There are four statutory criteria under the Mental Health Act $1983 .^{5}$ The first is that a patient has a mental disorder other than dependence on drugs and alcohol alone. ${ }^{6}$ Second, the disorder is of a nature or degree that warrants admission to hospital for assessment and/or treatment; ${ }^{7}$ nature refers to the particular disorder that the person is diagnosed with, its chronicity, prognosis and previous response to treatment for that disorder; ${ }^{8}$ degree refers to the current manifestations of the disorder. ${ }^{8}$ Third, admission is necessary in the interests of the patient's own health; and/or in the interests of the patient's own safety; ${ }^{9}$ and/or with a view to the protection of others. ${ }^{9}$ Compulsory admission is only deemed necessary if options within the community have failed and the patient cannot be admitted to hospital on a voluntary or informal basis. ${ }^{10}$ An additional criterion for detention under Section 3 is that appropriate medical treatment is available. ${ }^{11}$

A medical recommendation contains some pre-printed statements covering the criteria for detention that the doctor makes by signing the form. The doctor can delete some of these statements depending on whether they judge the detention necessary in the interests of health and/or safety and/or the protection of others. ${ }^{8}$ Following these pre-printed statements, there is a box, which would comfortably take 150 words, where the doctor, who is expected to know the legal requirements for detention, ${ }^{12-14}$ gives their reasons why the statutory criteria ${ }^{1}$ have been met and why detention is strictly necessary. ${ }^{4}$ If the patient is being detained under Section 3, there is space to enter the name of the hospital which will provide appropriate treatment and to which the patient is going to be admitted. Medical recommendations are subsequently scrutinised to see whether they show sufficient support for the assertions made on the form. ${ }^{15-18}$

The aim of this audit was to review the written reasons given for detention under Section 2 and Section 3 of the Mental Health Act and assess them against the goldstandard criteria based on the statutory requirements (Box 1)

\section{Method}

All medical recommendations for detention under Section 2 and 3 of the Mental Health Act written in November and December 2008 in Berkshire Healthcare NHS Foundation Trust and Oxford and Buckinghamshire Mental Health Partnership NHS Trust were reviewed by two assessors. The 
Box 1 Gold-standard criteria used to test the medical recommendations for detention

- Clear evidence to support the presence of a mental disorder

- A statement indicating its nature and/or degree

- Why it was in the interests of health, safety or the protection of others

- Why management in the community was not possible

- Why informal admission was not possible

assessors were psychiatrists who had expressed an interest in the audit and had a good command of English used in mental health records. They underwent $4 \mathrm{~h}$ of training by J.C. or J.M. During this training a consensus was reached as to what was a clear statement of reasons and when the reasons were just implied (Table 1).

Each of the recommendations was read by two assessors who checked legibility and whether the following were clearly present, implied or absent, as judged against the gold-standard criteria (Box 1):
1 an explicit statement about the presence of a named mental disorder and the reasons for believing this;

2 descriptions of degree and/or nature of the mental disorder that warranted 24-hour detention under care of responsible clinician;

3 reasons for 24-hour hospital detention and why a less restrictive option (management in the community) was not possible;

4 if the doctor stated that detention was in the interest of the patient's health, clear reasons why this was so;

5 if the doctor stated that detention was in the interests of patient safety, clear reasons why this was so;

6 if the doctor stated that detention was necessary for the protection of others, clear reasons why this was so;

7 reasons why informal admission was not justified.

In $8 \%$ of cases the two assessors were not in agreement whether the recommendation implied rather than clearly stated the reasons for compulsion. For each of these a third assessor was asked to arbitrate.

The results of the first cycle were disseminated electronically to all consultants, specialist registrars, registered Section 12-approved doctors, approved mental

\begin{tabular}{|c|c|c|}
\hline Criteria & $\begin{array}{l}\text { Clear statement } \\
\text { or implied }\end{array}$ & Example \\
\hline Mental disorder & $\begin{array}{l}\text { Implied } \\
\text { Clear }\end{array}$ & $\begin{array}{l}\text { 'He is mute with poor eye contact. He had been complaining in the days } \\
\text { before the interview of low mood. During the interview he was mute with } \\
\text { psychomotor retardation.' } \\
\text { 'He is suffering from a severe depressive episode, complaining of low mood } \\
\text { before the interview and when seen he was mute with poor eye contact } \\
\text { and psychomotor retardation.' }\end{array}$ \\
\hline Nature and degree & $\begin{array}{l}\text { Implied } \\
\text { Clear }\end{array}$ & $\begin{array}{l}\text { 'There had been several admissions in the past and she is complaining } \\
\text { of voices again.' } \\
\text { 'She is very distressed by third-person auditory hallucinations that talk about } \\
\text { her in a derogatory and threatening way. She has been detained } 5 \text { times } \\
\text { in the past } 2 \text { years with similar presentations. She has always responded } \\
\text { to antipsychotic medication.' }\end{array}$ \\
\hline Community not possible & $\begin{array}{l}\text { Implied } \\
\text { Clear }\end{array}$ & $\begin{array}{l}\text { 'He was very upset and his wife said things were quite tough at home.' } \\
\text { 'Despite the home treatment team visiting regularly to supervise } \\
\text { administration of medication, he had struck his wife on three separate } \\
\text { occasions. Management in the community is no longer safe for him or } \\
\text { his wife.' }\end{array}$ \\
\hline $\begin{array}{l}\text { In the interests } \\
\text { of patient's health }\end{array}$ & $\begin{array}{l}\text { Implied } \\
\text { Clear }\end{array}$ & $\begin{array}{l}\text { 'She had not been taking her medication and she was talking incessantly } \\
\text { about going to meet the queen.' } \\
\text { 'Her manic symptoms of grandiose delusions, pressure of speech and } \\
\text { psychomotor agitation need antipsychotic medication. Concordance will only } \\
\text { be possible as an in-patient.' }\end{array}$ \\
\hline $\begin{array}{l}\text { In the interests } \\
\text { of patient's safety }\end{array}$ & $\begin{array}{l}\text { Implied } \\
\text { Clear }\end{array}$ & $\begin{array}{l}\text { 'The patient has an array of depressive symptoms. There is an ongoing } \\
\text { suicidal risk.' } \\
\text { 'He has made several serious attempts at suicide in the past; he is currently } \\
\text { depressed and psychotic. The suicide risk can only be managed safely with } \\
\text { 24-hour in-patient observation.' }\end{array}$ \\
\hline $\begin{array}{l}\text { In the interests of the } \\
\text { safety of others }\end{array}$ & $\begin{array}{l}\text { Implied } \\
\text { Clear }\end{array}$ & $\begin{array}{l}\text { 'She has been making threats about her neighbours believing them to be } \\
\text { watching her with cameras in her flat.' } \\
\text { 'She has had three convictions for assault. While so psychotic, she is at high } \\
\text { risk of acting on her threats to attack her neighbours. This risk needs to be } \\
\text { managed with 24-hour in-patient observation.' }\end{array}$ \\
\hline $\begin{array}{l}\text { Informal admission } \\
\text { not possible }\end{array}$ & $\begin{array}{l}\text { Implied } \\
\text { Clear }\end{array}$ & $\begin{array}{l}\text { 'He lacks insight and does not understand the reasons for admission.' } \\
\text { 'He lacks insight or capacity to decide about admission. His needs cannot } \\
\text { be met by the Mental Capacity Act nor is he agreeing to a hospital } \\
\text { admission.' }\end{array}$ \\
\hline
\end{tabular}




\section{Box 2 Aide-memoire}

When documenting reasons for detention we suggest five clear statements, as follows:

Patient ' $A$ ' has 'such and such' a mental disorder characterised by the following symptoms

The nature of their disorder is demonstrated by AND/OR The degree of their disorder is demonstrated by

Community treatment is not possible because and this makes 24-hour specialist hospital admission necessary.

Hospital admission is necessary in the interests of 'A's' health because he or she needs___; in the interests of patient 'A's' safety to manage the risks of___ ; and for the protection of others to manage the risks of

Informal admission is not possible because Patient $A$ is not agreeing to admission, AND/OR the established nature of their mental disorder strongly indicates that they will not sustain a commitment to informal admission AND/OR the patient lacks capacity but the patient's needs cannot be appropriately met by relying on the Mental Capacity act alone.

health practitioners (AMHPs) and scrutineers. An aidememoire (Box 2) was sent with the results so that all doctors who completed the forms, and AMHPs who accepted them, had a template of what should be included in the reasons for detention.

This generated questions and discussion and time was taken to answer all these questions by email. Across the two trusts there were only 12 doctors ( 5 independent and 7 trust doctors) who were present at over $80 \%$ of Mental Health Act assessments that resulted in detention. These doctors were approached individually and informed about the results of the audit and what would be considered best practice. The results of the first cycle were presented to the relevant Mental Health Act committees in each trust and appropriate educational forums. Following this period of feedback, the second audit cycle took place. This was in March and April 2009 in Oxford and Buckinghamshire and in September and October 2009 in Berkshire.

\section{Results}

\section{Number of recommendations and grade of doctor signing them}

In the first cycle of the audit, 214 medical recommendations signed by 350 doctors were received in the two trusts; 78 were separate and 136 were joint recommendations. A total of 175 patients were detained, 99 under Section 2 and 76 under Section 3. In the second cycle, the trusts received 202 medical recommendations signed by 352 doctors, 52 separate and 150 joint. There were 176 patients detained, 108 under Section 2 and 68 under Section 3. The breakdown of doctors signing recommendations by grade for both audit cycles is given in Table 2 .
Table 2 Grade of total number of doctors signing recommendation

\begin{tabular}{lcc}
\multirow{2}{*}{ Grade } & \multicolumn{2}{c}{$n(\%)$} \\
\cline { 2 - 3 } Consultants & $71(20)$ & $63(18)$ \\
\hline General practitioners & $17(5)$ & $10(3)$ \\
\hline Independent doctors & $162(46)$ & $140(39)$ \\
\hline Trust doctors & $44(13)$ & $66(19)$ \\
\hline Specialist registrars/specialty trainees & $56(16)$ & $74(21)$
\end{tabular}

a. $n=350$

b. $n=352$.

In both cycles of the audit there was no statistical difference in the quality of the recommendations between the different grades of doctors as measured against the gold standard.

\section{Appropriate medical treatment}

In all of the Section 3 forms a suitable hospital for medical treatment was entered. Similarly, all the patients detained under Section 2 were received for assessment and treatment in psychiatric hospitals that were suitable for this purpose. However, we did not look for a specific statement in the Section 2 recommendations regarding this.

\section{Legibility}

In both cycles all written recommendations were deemed to be sufficiently legible (Table 3 ).

Improvements were observed for all the statutory criteria in the second cycle. The doctors were weakest at giving reasons why detention was in the interests of health and/or safety and/or the protection of others, and even after the second cycle there was room for improvement here.

A recurring mistake made by doctors was that if a patient was deemed to be lacking in capacity to consent to hospital admission or to be without insight, this was deemed sufficient reason for compulsion rather than informal admission. It is worth remembering that if a patient has no capacity, compulsion is only necessary if they cannot be ensured appropriate and necessary treatment under the Mental Capacity Act. ${ }^{13,19,20}$

\section{Discussion}

Our data are comparable with other studies. ${ }^{21}$ As many as 99\% (first cycle) and 98\% (second cycle) of recommendations stated that it was in the interests of the patient's health to be detained; $94 \%$ and $85 \%$ stated that it was in the interests of safety; and $63 \%$ and $56 \%$ stated that it was for the protection of others. Similar results were reported elsewhere. $^{21}$

We acknowledge that deciding whether reasons for detention are implied or clearly stated is a matter of judgement about which there could be disagreement and is frequently a test of the use of English as much as it is a test of understanding the legal requirements for detention. 
Table 3 Quality of reasons or description given for each of the statutory criteria in the two cycles of the audit

\begin{tabular}{|c|c|c|c|c|}
\hline \multirow[b]{2}{*}{ Statutory criteria } & \multirow[b]{2}{*}{ Cycle } & \multicolumn{3}{|c|}{$n(\%)$} \\
\hline & & None given & Implied & Clear statement \\
\hline Mental disorder & $\begin{array}{l}1 \text { st }, n=214 \\
2 n d, n=202\end{array}$ & $\begin{array}{l}40(19) \\
9(4.5)\end{array}$ & $\begin{array}{l}20(9) \\
17(8.5)\end{array}$ & $\begin{array}{l}154(72) \\
176(87)\end{array}$ \\
\hline Nature and degree & $\begin{array}{l}1 \text { st }, n=214 \\
2 n d, n=202\end{array}$ & $\begin{array}{r}11(5) \\
8(4)\end{array}$ & $\begin{array}{l}32(15) \\
19(9.5)\end{array}$ & $\begin{array}{l}171(80) \\
175(86.5)\end{array}$ \\
\hline Community not possible & $\begin{array}{r}1 \text { st }, n=214 \\
2 n d, n=202\end{array}$ & $\begin{array}{l}79(37) \\
23(11)\end{array}$ & $\begin{array}{l}67(31) \\
32(16)\end{array}$ & $\begin{array}{c}68(32) \\
147(73)\end{array}$ \\
\hline Interests of health & $\begin{array}{r}1 \text { st }, n=212 \\
2 n d, n=197\end{array}$ & $\begin{array}{c}47(22) \\
6(3)\end{array}$ & $\begin{array}{r}135(64) \\
65(33)\end{array}$ & $\begin{array}{r}30(14) \\
126(64)\end{array}$ \\
\hline Interests of safety & $\begin{array}{r}1 \text { st }, n=202 \\
2 n d, n=171\end{array}$ & $\begin{array}{l}60(30) \\
12(7)\end{array}$ & $\begin{array}{r}117(58) \\
56(33)\end{array}$ & $\begin{array}{r}25(12) \\
103(60)\end{array}$ \\
\hline Protection of others & $\begin{array}{l}\text { 1st, } n=134 \\
2 n d, n=114\end{array}$ & $\begin{array}{l}43(32) \\
14(12)\end{array}$ & $\begin{array}{l}79(59) \\
37(32.5)\end{array}$ & $\begin{array}{l}12(9) \\
63(55.5)\end{array}$ \\
\hline Informal admission not possible & $\begin{array}{r}1 \text { st }, n=214 \\
2 n d, n=202\end{array}$ & $\begin{array}{l}46(21) \\
28(14)\end{array}$ & $\begin{array}{l}40(19) \\
32(16)\end{array}$ & $\begin{array}{l}128(60) \\
142(70)\end{array}$ \\
\hline
\end{tabular}

However, absence or clear presence of reasons is something that the two assessors could be confident about.

The overarching impression was that although doctors are able to describe the clinical features of a patient with a mental disorder, they have more difficulty clearly focusing on the statutory criteria and providing brief evidence to support their conclusions. The first cycle confirmed that doctors were most consistent at documenting the mental disorder (72\%) and its nature and/or degree (80\%). A clear description of a mental disorder and its nature and degree may imply that detention is necessary but it is not the equivalent of giving clear reasons. Similar to other studies, ${ }^{22-25}$ our audit showed that doctors were far less clear about the legal requirements for detention, namely, explaining why assessment and/or treatment in hospital was necessary; that alternatives to detention in hospital had been considered; and why informal admission was not possible. It was as though doctors thought like this: 'I have found this patient to be showing obvious signs and symptoms of a mental illness, therefore they should be detained in hospital'. They had missed out showing essential steps in their reasoning, that is, why it was necessary in the interests of health, safety and protection of others for the patient to be in hospital; and careful consideration of the two prerequisites for compulsion. First, that less restrictive alternatives to detention had been entertained and were deemed to be unsuitable or had failed..$^{10,14,18,23}$ Second, that informal admission was not possible for good reason. After the second cycle there was still significant room for improvement in these areas.

After completing the first cycle of the audit the data were generally well received and particularly the independent doctors were glad to have feedback to improve practice. The gold standard was universally accepted by all Section 12-approved doctors with whom we discussed it. A personal approach to individual doctors who completed a large number of recommendations was helpful in getting doctors to accept that there are clear standards for medical recommendations and subsequently recording them. The aide-memoire was very well received and doctors found it helpful in improving the standard of recommendations. For some senior psychiatrists who had performed the role of scrutineer in the past, there was a paradoxical resistance to a systematic, standardised approach to giving the reasons for detention. Even though they accepted the rationale for each of the criteria, they preferred a reliance on trusted expert opinion rather than pre-set standards, believing that the form was inviting to give their opinion rather than justifying detention against an established legal framework. During discussions about the audit, views about this did not shift. Although not measured in the audit, J.M. (scrutineer for Berkshire) has found that returning recommendations for amendment ${ }^{18}$ rapidly changed doctors' willingness to use accepted criteria. Our suggestion would be that recommendations should be returned when any of the following are missing: a clear description of a recognisable mental disorder that warrants admission; clear reasons why the patient cannot be managed in the community; and an appropriate justification of why the patient cannot be admitted informally. To maintain standards of completion scrutineers should be ready to return forms for amendment irrespective of the seniority or standing of the doctor who completed them. ${ }^{18}$ Above all, scrutineers should be able to give a clear explanation of the reasons they do not support the conclusions.

There is no space on Section 2 forms to record the name of the hospital where appropriate assessment and treatment can be provided. A period of assessment is as much a specialist intervention as medical treatment. It would seem right in the spirit of the Mental Health Act that patients detained for a period of assessment were going to a hospital capable of carrying out this very important medical process.

Many doctors complained that during Section 12 training they had not received formal instruction on the completion of medical recommendations. They reported being taught about the background to the Mental Health Act and the meaning of such terms as 'deprivation of liberty' and 'mental disorder', but not what should be included in medical recommendations and what was considered to be a 
reasonable medical examination during a Mental Health Act assessment. This audit suggests that Section 12 training should include systematic teaching on what is expected in medical recommendations.

\section{About the authors}

Julian Mason Scrutineer for Berkshire Healthcare Foundation NHS Trust, Hannah Roberts F2 in Psychiatry, Rebecca Northridge F2 in Psychiatry, Oxford and Buckinghamshire Mental Health Partnership NHS Trust, Garyfallia Fountoulaki Consultant General Adult Psychiatrist, Berkshire Healthcare NHS Foundation Trust, Emma Andrews A-level student, Kingsbridge Community Colleage, Devon, Cassie Watcyn-Jones Mental Health Act Administrator, Berkshire Healthcare NHS Foundation Trust, Terri Manion Mental Health Act Administrator, Oxford and Buckinghamshire Mental Health Partnership NHS Trust, Julie Chalmers Lead Clinician for Oxford and Buckinghamshire Mental Health Partnership NHS Trust for application of the Mental Health Act, Phil Davison Consultant General Adult Psychiatrist, Oxford and Buckinghamshire Mental Health Partnership NHS Trust.

\section{References}

1 Mental Health Act Commission. The threshold for use of the 1983 Act In 10th Biennial Report, 2001- 2003: Placed Among Strangers: 87-116. TSO (The Stationery Office), 2003.

2 Fennell P. Section 12 approved doctors. In Mental Health: The New Law (Jordans' New Law Series): 72. Jordans, 2007.

3 Bartlett P, Sandland R. The writ of habeas corpus in the medical recommendations in the process of civil confinement. In Mental Health Law Policy and Practice: 187-90. Oxford University Press, 2007.

4 Jones RM. General provisions as to medical recommendations. In Mental Health Act Manual: 87-93. Thomson, Sweet and Maxwell, 2008.

5 Zigmond T. A new Mental Health Act for England and Wales: grounds for compulsion. Adv Psychiatr Treat 2004; 10: 243-6.

6 Fennell P. Defining mental disorder in mental health: the new law. In Mental Health: The New Law (Jordans' New Law Series): 17-9. Jordans, 2007

7 Mental Health Act Commission. $R$ (on the application of the secretary of state for the Home Department) $v$ MHRT and (1) DH (2) South West London \& St George's Mental Health NHS Trust. Quoted and discussed in The Mental Health Act in the courts. In The Eleventh Biennial Report 2003-2005: In Place of Fear? TSO (The Stationery Office), 2006: 91.

8 Department of Health. Application for detention in hospital. In Code of Practice Mental Health Act 1983: 24-50. TSO (The Stationery Office), 2008.
9 Fennell P. Necessary in the interests of the patients' health or safety or for the protection of others and the treatment cannot be provided unless he is detained under this section. In Mental Health: The New Law (Jordans' New Law Series): 153. Jordans, 2007.

10 Fennell P. Mental disorder of a kind or degree warranting confinement. In Mental Health: The New Law (Jordans' New Law Series): 66-7. Jordans, 2007.

11 Fennell P. Replacing treatability with availability of appropriate treatment. In Mental Health: The New Law (Jordans' New Law Series): 67-9. Jordans, 2007.

12 Bartlett P, Sandland R. The medical recommendations. In Mental Health Law: Policy and Practice: 174-7. Oxford University Press, 2007.

13 Mental Health Act Commission. The interface between the Mental Capacity and Mental Health Act. In The Eleventh Biennial Report 20032005: In Place of Fear?: 176-80. TSO (The Stationery Office), 2006.

14 Fennell P. Medical recommendations and section 12 approved doctors. In Mental Health: The New Law (Jordans' New Law Series): 84-7. Jordans, 2007

15 Bartlett $P$, Sandland R. Scrutiny and rectification of documentation on arrival at hospital in the process of civil confinement. In Mental Health Law: Policy and Practice: 183-5. Oxford University Press, 2007.

16 Department of Health. Receipt and scrutiny of documents. In Mental Health Act Code of Practice: 103-6. TSO (The Stationery Office), 2008

17 Keywood K. Rectification of incorrect documentation under the Mental Health Act 1983. J Forens Psychiatry 1996; 7: 79-81.

18 Jones RM. Rectification of applications and recommendations. In Mental Health Act Manual: 87-93. Thomson, Sweet \& Maxwell, 2008.

19 Eastman N, Peay J. Bournewood: an indefensible gap in mental health law. BMJ 1999; 317: 94-5.

20 Fennell P. Patients who lack capacity to consent to treatment or admission. In Mental Health: The New Law (Jordans' New Law Series): 122. Jordans, 2007.

21 Wall S, Churchill R, Hotopf M. A Systematic Review of Research Relating to the Mental Health Act 1983. Department of Health, 1999.

22 Bhatti V, Kenney-Herbert JP, Cope RV. Knowledge of Current Mental Health legislation among medical practitioners approved under section 12(2) of the mental health act 1983 in the West Midlands. Health Trends 1999; 30: 106-8.

23 Peay J, Roberts C, Eastman N. Knowledge of mental health law of practitioners and responsibilities under the Mental Health Act (1983): a national survey. J Ment Health Law 2001; 1: 44-5.

24 Peay J, Roberts C, Eastman N. Mental health professionals' attitudes towards legal compulsion: report of a national survey. Int J Forens Ment Health 2002; 1: 71-82.

25 Humphreys MS, Kenney-Herbert JP, Cope RV. How to keep up with the Mental Health Act. Adv Psychiatr Treat 2000; 6: 407-11. 